\title{
Stand for cyclic tests of rack and pinion steering mechanism
}

\author{
N. S. Solomatin, V. A. Ivliev* , L. A. Cherepanov, and D. A. Kolodkin \\ Togliatti State University, 14, Belorusskaya St., Togliatti, Russia
}

\begin{abstract}
At the present moment the motor vehicle designers pay particular attention to the vehicle active safety aspects. Steering control plays a significant role here, since its slightest malfunction may result in very unpleasant consequences. Therefore, specific attention is paid to the improvement of the steering control quality and reliability. This article presents the design of a stand for testing steering mechanisms of various dimensions through application of torque at numeral angles; the torque application aims to improve the vehicle active safety.
\end{abstract}

The motor vehicle tests allow us to assess the technical level and quality of a product at its life cycle stages and to make scientifically based decisions on the following aspects:

- changing the units design;

- using certain materials in the production of the units parts;

- units maintenance regulations[1,2].

Longevity testing is performed to obtain numerical reliability. This sort of testing is very labor-intensive and involves heavy economic expenditures. However, the units manufacturer is obliged to analyze the products that failed during the testing process and, based on this analysis, to develop the necessary procedures to eliminate the faults[3]. The analysis is based on the following tests:

- static and dynamic tests of the vehicle assemblies and parts; these tests are required to determine the elements' total margins of safety and durability;

- vibration and fatigue tests that allow to determine a product lifespan;

- wear tests of certain mating components and mechanisms;

- parametric reliability tests that allow to assess functioning accuracy, efficiency and other performance characteristics of product units and their changes over time.

The actions aimed to improve the motor vehicle units quality and reliability are carried out throughout the entire period of its production and include, among other things, periodic production tests, as well as steering mechanisms cyclic tests.

Steering mechanisms ensure the active car safety, therefore, the production process must include the quality control both during the individual parts manufacture and after the product assembly. Modern steering systems with electrically assisted steering bear significantly heavier loads than the systems with hydraulic steering booster, since the steering rack piston of the hydraulic steering booster bears road unevenness shocks and

* Corresponding author: ivliev.alex163@yandex.ru 
reduces the effort transmitted to the steering gear. Therefore, we may conclude that it is necessary to carry out endurance tests during the steering mechanism production.

The stand for cyclic testing of rack and pinion steering mechanisms for compliance with the reliability and durability requirements must ensure that a steering mechanism is installed on the stand and the load modes are set the same way as in a car in actual operating conditions.

The stand should be equipped with variable fittings to enable testing of steering mechanisms of various sizes and configurations:

- the distance between the inboard joint centers is from 400 to $900 \mathrm{~mm}$;

- the angle between the primary shaft axis and the steering rack axis is $\pm 60^{\circ}$;

- the angle of vertical application of torque is from 0 to $50^{\circ}$;

- the extension of the steering mechanism drive pinion shaft is from 50 to $200 \mathrm{~mm}$;

- the axle spacing along the steering mechanism supports is from 50 to $300 \mathrm{~mm}$;

- the steering mechanism rack stop position is from 100 to $300 \mathrm{~mm}$.

We analyzed the existing test $[4,5,6]$ stands for steering mechanisms and came to the conclusion that the stand developed by the BIA company (fig.1) is the one best suited for providing final quality control of finished goods and eliminating the possibility of output parameters not matching the set performance characteristics that a product is required to have. However, this facility does not meet the above-mentioned requirements to the full extent.

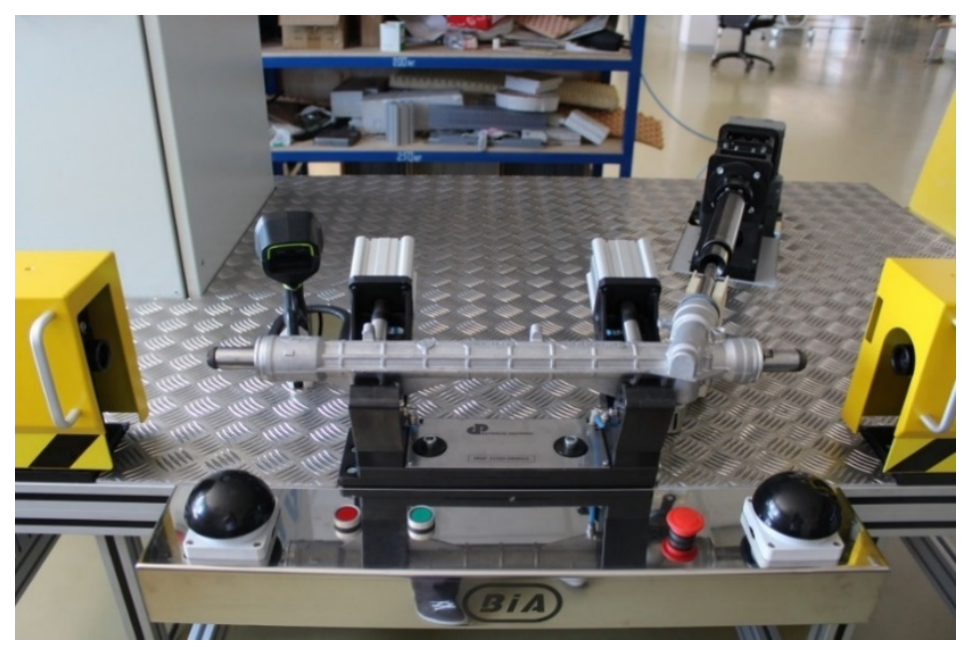

Fig. 1. Stand for tests of rack and pinion steering mechanisms (BIA brand)

The Vehicles Design and Operation Division of the Togliatti State University developed the design of a stand for testing rack and pinion steering mechanism; this facility can create torque on the steering mechanism shaft, applied at various angles both in vertical and horizontal directions. To create it, we recommend using a synchronous three-phase brushless direct current motor along with a coaxial two-stage planetary reduction gearbox. The TRB-10K series sensor ensures that torque is measured to a high precision; this sensor also allows to measure shaft rotation angles and the shaft angular velocity.

The steering mechanism is loaded by an axial piston hydraulic motor; rods and shafts connect it to steering rod ends in a way that ensures uniform resistance throughout the entire range of the steering mechanism rack movement (Fig.2). 


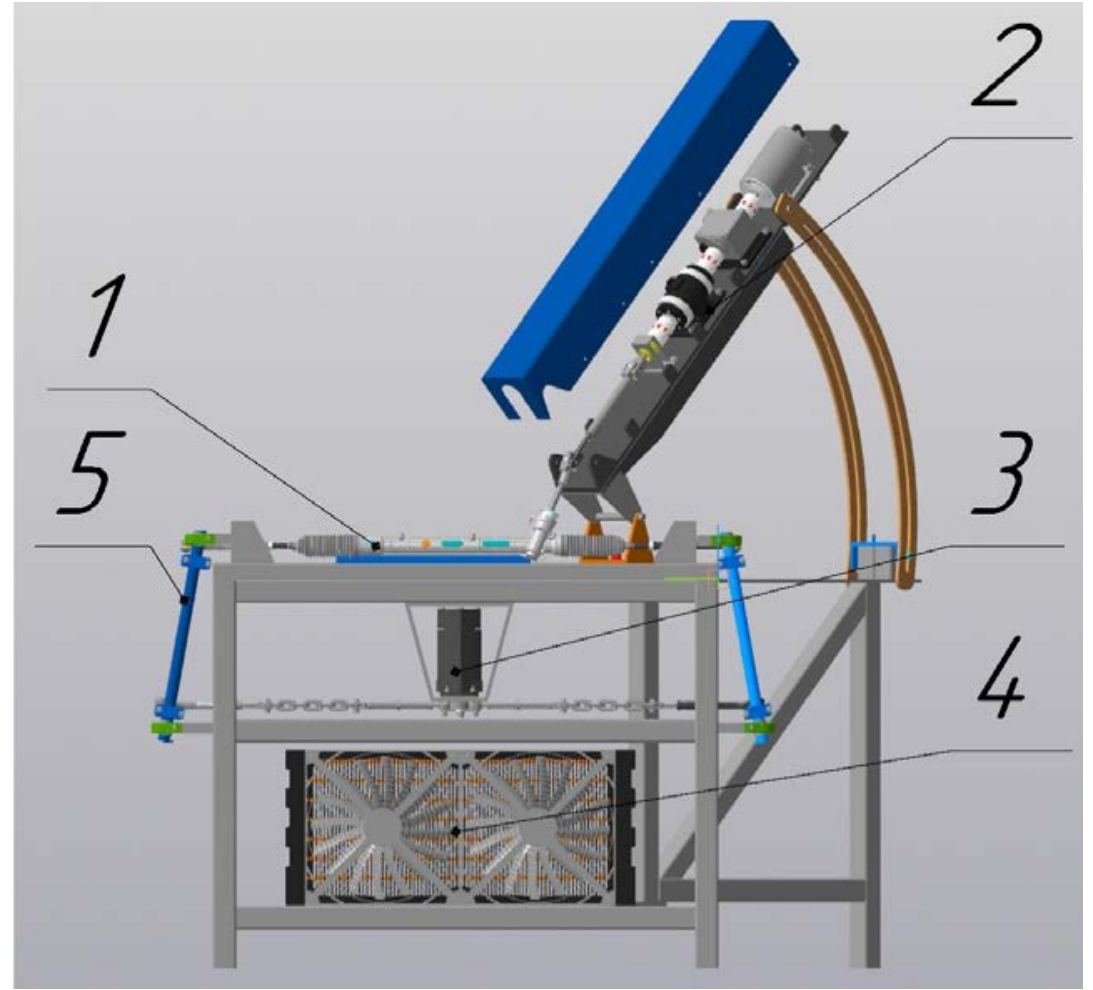

1 - steering mechanism; 2 - drive mechanism; 3 - loading mechanism; 4 - service fluid cooling system; 5 - shaft with pivot rods, assembled;

Fig. 2. General view of stand for cyclic tests of rack and pinion steering mechanism

Conclusion: this article presents the developed design of the universal stand for cyclic tests of rack and pinion steering mechanisms of various motor vehicles.

\section{References}

1. Grishkevich A.I. \& Vysotsky M.S. (editors) (1991). Motor vehicles: tests, a study guide for universities. Minsk: Vysheyshaya shkola.

2. Solomatin N.S. (2013). Testing vehicle components, units and systems. Togliatti: TGU.

3. Kozlovtsev D.V. \& Poluektov M.V. (2017). General analysis of the modern car steering control malfunctions. Molodoy ucheniy - Young scientist, 10 (144), 61-64. URL: https://moluch.ru/archive/144/40367/ (date of access: October 15, 2020)

4. Ivanov V.A. (1999). Stand for testing and repairing hydraulic steering booster. Avtomobilnaya promyshlennost - Automotive industry, 6, 28-30.

5. All-Russia Research and Development and Technology Institute of Machine and Tractor Fleet Operation and Repair (applicant and patent holder) (2001). Patent RF 2173414 MPK7 F 15 B 19/00.Stand for testing the elements of steering control hydraulic unit. Date of application: June 27, 2000. Date of publication: September 10, 2001.

6. Machinery, units and processes. Design, development and modernization: materials of the international scientific and practical conference (2018). Saint Petersburg: SPbF NIC MS, 1. 